\title{
Anaemia in hospitalised preschool children from a rural area in Mozambique: a case control study in search for aetiological agents
}

Cinta Moraleda ${ }^{1,2^{*}}$ (D), Ruth Aguilar ${ }^{1,2,3}$, Llorenç Quintó ${ }^{1}$, Tacilta Nhampossa ${ }^{2}$, Montserrat Renom ${ }^{1,2}$, Augusto Nhabomba², Sozinho Acácio², John J. Aponte ${ }^{1,2}$, Delino Nhalungo ${ }^{2}$, Ariel H. Achtman ${ }^{4,5}$, Louis Schofield ${ }^{4,5,6}$, Helder Martins ${ }^{2}$, Eusebio Macete ${ }^{2,7}$, Pedro L. Alonso ${ }^{1,2}$ and Clara Menéndez ${ }^{1,2,3}$

\begin{abstract}
Background: Young children bear the world's highest prevalence of anaemia, the majority of which is of multifactorial aetiology, which in turn hampers its successful prevention. Even moderate degrees of anaemia are associated with increased mortality and morbidity. Despite this evidence, there is a lack of effective preventive programs and absence of consensus in the safety of iron supplementation in malaria areas, which reflects the poor understanding of the contribution of different aetiologies to anaemia. In order to reduce the anaemia burden in the most vulnerable population, a study to determine the aetiology of anaemia among pre-school Mozambican children was performed.

Methods: We undertook a case-control study of 443 preschool hospitalized children with anaemia (haemoglobin concentration $<11 \mathrm{~g} / \mathrm{dl}$ ) and 289 community controls without anaemia. Inclusion criteria were: age 1-59 months, no blood transfusion in the previous month, residence in the study area and signed informed consent. Both univariable and multivariable logistic regression analyses were performed to identify factors associated with anaemia and adjusted attributable fractions (AAF) were estimated when appropriate.

Results: Malaria (adjusted odds ratio $(A O R)=8.39, p<0.0001 ; A A F=37 \%)$, underweight $(A O R=8.10, p<0.0001$; $\mathrm{AAF}=43 \%)$, prealbumin deficiency $(\mathrm{AOR}=7.11, p<0.0001 ; \mathrm{AAF}=77 \%)$, albumin deficiency $(\mathrm{AOR}=4.29, p=0.0012$; $\mathrm{AAF}=30 \%), \mathrm{HIV}(\mathrm{AOR}=5.73, p=0.0060 ; \mathrm{AAF}=18 \%)$, and iron deficiency $(\mathrm{AOR}=4.05, p<0.0001 ; \mathrm{AAF}=53 \%)$ were associated with anaemia. Vitamin A deficiency and a-thalassaemia were frequent (69\% and 64\%, respectively in cases) but not independently related to anaemia. Bacteraemia (odds ratio $(\mathrm{OR})=8.49, p=0.004$ ), Parvovirus-B19 $(\mathrm{OR}=6.05, p=0.017)$ and Epstein-Barr virus $(\mathrm{OR}=2.10, p=0.0015)$ infections were related to anaemia only in the unadjusted analysis. Neither vitamin B12 deficiency nor intestinal parasites were associated with anaemia. Folate deficiency was not observed.

(Continued on next page)
\end{abstract}

* Correspondence: cinta.moraleda@isglobal.org

${ }^{1}$ ISGlobal, Barcelona Ctr. Int. Health Res. (CRESIB), Hospital Clínic - Universitat de Barcelona, Barcelona, Spain

${ }^{2}$ Manhiça Health Research Center (CISM), Manhiça, Mozambique

Full list of author information is available at the end of the article

(c) The Author(s). 2017 Open Access This article is distributed under the terms of the Creative Commons Attribution 4.0 International License (http://creativecommons.org/licenses/by/4.0/), which permits unrestricted use, distribution, and reproduction in any medium, provided you give appropriate credit to the original author(s) and the source, provide a link to the Creative Commons license, and indicate if changes were made. The Creative Commons Public Domain Dedication waiver (http://creativecommons.org/publicdomain/zero/1.0/) applies to the data made available in this article, unless otherwise stated. 
(Continued from previous page)

Conclusions: Undernutrition, iron deficiency, malaria, and HIV are main factors related to anaemia in hospitalised Mozambican preschool children. Effective programs and strategies for the prevention and management of these conditions need to be reinforced. Specifically, prevention of iron deficiency that accounted in this study for more than half of anaemia cases would have a high impact in reducing the burden of anaemia in children living under similar conditions. However this deficiency, a common preventable and treatable condition, remains neglected by the international public health community.

Keywords: Anaemia, Iron deficiency, Children, Sub-Saharan Africa, Malaria, HIV

\section{Background}

Despite significant improvements over the last two decades, global anaemia prevalence in 2010 was 33\%, causing 68 million years lived with disability, more than other major causes such as chronic respiratory diseases, with SubSaharan Africa being the most affected region [1, 2]. Anaemia increases the risk of child mortality while iron deficiency (ID) has consequences on cognitive and physical development of children $[3,4]$. Young children had the highest prevalence in all areas, being this age group the only in which anaemia prevalence increased from 1990 to 2010 [2]. Previous information from Mozambique showed that $74.7 \%$ of children between 6 months and 5 years were anemic, having haemoglobin $(\mathrm{Hb}) \leq 5 \mathrm{gr} / \mathrm{dl} 11.5 \%$ of them [5]. Mean $\mathrm{Hb}$ concentration showed insignificant differences between regions [5]. In Mozambique anaemia has been reported by the Ministry of Health to be the main nutritional disease since 1996, but no information about the aetiology is available $[6,7]$.

Despite causing such high levels of disability, the public health community does not pay anaemia the attention it deserves. This lack of prioritisation may be partly due to the habit of treating anaemia as a byproduct of other disease processes [3, 8]. Therefore, the World Health Organization (WHO) has emphasised the need of addressing the aetiology of anaemia in different populations [8]. In addition, the WHO guidelines for prevention of ID [3], are rarely implemented due to the commonly held view that iron supplementation increases the susceptibility to some infectious diseases mainly in non-iron deficient children, and the lack of iron status markers in low income settings [9]. With the aim of providing evidence to guide control policies, a study to determine the anaemia risk factors was undertaken in hospitalised pre-school children in rural Mozambique, where the causes of anaemia are poorly understood $[6,7]$.

\section{Methods}

\section{Study design}

The study was conducted at the Centro de Investigação em Saúde de Manhiça (CISM) and the Manhiça District
Hospital (MDH), Southern Mozambique. The CISM runs a continuous Demographic Surveillance System (DSS) and round-the-clock morbidity surveillance at the $\mathrm{MDH}$. The area has been described in detail elsewhere [10]. Briefly, malaria was main cause of death in the area (21.8\% of cases) followed by pneumonia (9.8\%), HIV/ AIDS (8.3\%) and diarrhoea (8\%) [11]. Malaria transmission is perennial with marked seasonality and mainly due to Plasmodium falciparum [12]. The HIV prevalence in adults (18-47 years of age) was $37.5 \%$ [13] and $1.4 \%$ in children $\leq 11$ years old [14]. The HIV-mother-to-childtransmission rates in the first month and at 12 months of age were $9 \%$ and $27 \%$, respectively [15]. Almost half (47\%) of children visited in the out-patient clinic presented some degree of undernutrition being $6 \%$ of them severely malnourished [16].

A case-control study was designed to recruit 450 hospital anaemia cases and 450 community controls. All children with clinical criteria for hospital admission with ages of 1-59 months, no history of blood transfusion in the previous month and residence in the CISM DSS area were offered participation in the study. $\mathrm{Hb}$ levels were determined with the Hemocue HB $201^{+}$system (Änghelom, Sweden) in children whose guardians signed the informed consent and those with $\mathrm{Hb}<11 \mathrm{~g} /$ dl were recruited as cases. Recruitment was consecutive, from October 2008 to August 2010, running continuously during working hours (8:00-16:00). In order to avoid the confounding effect of malaria seasonality, a maximum of ten cases per week were recruited until reaching 450 cases.

Community controls were randomly selected from the DSS among children between 1 and 59 months of age, and visited at home by project personnel. $\mathrm{Hb}$ levels were determined by Hemocue in children with no history of blood transfusion in the previous month whose guardians had signed the informed consent. Those with $\mathrm{Hb} \geq 11 \mathrm{~g} / \mathrm{dl}$ were invited to a study visit at the MDH. Due to the high prevalence of anaemic children in the community (91\%) (unpublished data), only 289 community controls were recruited. Enrolment of cases and controls occurred concurrently. 
The recruitment of hospital controls, which would have allowed ruling out possible confounding factors associated with being severely sick, was not possible due to the extremely high prevalence of anaemia among admitted children in this setting. Similarly, due to the high prevalence of anaemia in the community, it was not possible to enrol the planned sample size of controls. The implications of this limitation on the results would depend on the assumptions made as to the proportion of controls exposed to the factor.

The results of the clinical examination and sociodemographic information were entered into standardised questionnaires. Four $\mathrm{mL}$ of venous blood was drawn, blood smears and filter paper blood smears were made. A maximum of $1 \mathrm{ml} / \mathrm{kg}$ was drawn from children. A stool and a urine sample were collected whenever possible.

\section{Laboratory methods}

Haematological studies

Blood counts, different from haemoglobin, were performed using a Sysmex analyser KX21N or XT-2000i (Sysmex Long Grove, IL, USA). Reticulocyte counts were estimated by microscopy on cresil blue-stained blood smears.

\section{Biochemical studies}

Albumin, prealbumin, and C-reactive protein (CRP) levels were measured with an ADVIA 2400 analyser (Siemens Healthcare, Spain). Folic acid, vitamin B12 and ferritin levels were measured with an ADVIA Centaur (Siemens Healthcare, Spain). sTfR levels were measured in a BN-II nephelometer (Dade-Siemens Healthcare, Spain) and vitamin A levels by reversed phase high-performance liquid chromatography [17]. Erythropoietin quantification was performed using the Quantikine human erythropoietin immunoassay kit (R\&D Systems, USA).

\section{Bacteriological, virological and parasitological studies}

Bacteria were detected in blood cultures in the BAC TEC $^{\oplus} 9050$ (Becton-Dickinson, USA). In children $\leq 18$ months of age HIV infection was defined as a HIV-1 DNA-positive result, detected using the Amplicor HIV-1 DNA-PCR kit (Roche Diagnostics, USA) and in older children it was defined as two positive rapid tests, using the Determine HIV-1/2 Rapid Test (Abbott Laboratories, USA) and confirming by the Uni-Gold Rapid Test (Trinity Biotech Co., Ireland), or as discordant rapid test results resolved by an additional HIV DNA-positive result. Epstein-Barr virus (EBV) and Parvovirus B19 (PV-B19) were identified by real time quantitative PCR (qPCR) using the Artus PCR kits (QIAGEN, Spain). Plasmodium falciparum (Pf) parasites were identified by microscopy on Giemsa-stained blood films. Pf qPCR was performed for microscopically negative samples. Schistosoma haematobium was determined by direct microscopic examination of urine sediment [18]. Intestinal parasites in stool (see Table 3 for details) were detected by microscopic examination using the merthiolate-iodine-formalin concentrations method [19].

\section{Genetic studies}

Haemoglobinopathies and $\beta$-thalassaemia were assessed using the $\beta$-thalassaemia Short Program from the Variant Haemoglobin Testing System ${ }^{\odot}$ (Bio-Rad, Hercules, USA). Detection of $\alpha$-thalassaemia (3.7 $\mathrm{kb}$ deletion) was performed by the GAP-PCR method [20]. Glucose 6phosphate dehydrogenase (G6PD) deficiency was determined using the Beutler fluorescent spot test [21].

\section{Definitions}

Anaemia was categorised as severe $(\mathrm{Hb}<5 \mathrm{~g} / \mathrm{dl})$ or moderate $(\mathrm{Hb} \geq 5 \mathrm{~g} / \mathrm{dl}$ to $<11 \mathrm{~g} / \mathrm{dl})$. Fever was defined as axillary temperature $\geq 37.5{ }^{\circ} \mathrm{C}$. Bacteraemia was defined as at least one bacterium isolated in blood (excluding common contaminants listed in Table 3). Pf infection was defined as the presence of asexual parasites in blood by microscopy or qPCR. Clinical malaria was defined as $P f$ infection plus fever or a history of fever in the preceding $24 \mathrm{~h}$. Detection of parasites by qPCR and a negative blood smear defined submicroscopic $P f$ infections. Hyperparasitaemic $P f$ infection was defined as $>100,000$ parasites/ $\mu$ l of blood. EBV and PV-B19 infections were defined as detection of the virus in blood by qPCR.

Wasting was defined as a weight-for-height/length Zscore (WHZ) of $<-2$ standard deviations (SD), stunting as height-for-age $\mathrm{Z}$-score $(\mathrm{HAZ})<-2 \mathrm{SD}$ and underweight as weight-for-age $Z$ score (WAZ) $<-2$ SD [22]. Albumin deficiency was defined as $<34 \mathrm{~g} / \mathrm{l}$ (laboratory reference value), and prealbumin deficiency as $<0.142 \mathrm{~g} / \mathrm{l}$ in children $<6$ months of age, $<0.120 \mathrm{~g} / \mathrm{l}$ in children $6-$ 12 months of age and $<0.108 \mathrm{~g} / \mathrm{l}$ in children $13-59$ months of age [23]. Folate deficiency was defined as $<3 \mathrm{ng} / \mathrm{ml}$ (laboratory reference value), vitamin A deficiency as $<20 \mu \mathrm{g} / \mathrm{dl}$ [24], and vitamin B12 deficiency as $<200 \mathrm{pg} / \mathrm{ml}$ [25]. ID was defined as the ratio of soluble transferrin receptor to $\log$ ferritin (TfR-F index) $>1.5$ if CRP $<1 \mathrm{mg} / \mathrm{dl}$, and $>0.8$ if CRP $\geq 1 \mathrm{mg} / \mathrm{dl}$. This biomarker was identified as the best predictor of ID with an accuracy of $71 \%$, using the bone marrow iron content as the gold standard [9]. In order to compare ID prevalence between cases and controls, this ID definition was used instead of bone marrow iron content, as bone marrow examination was undertaken in anaemic children only [9]. Inflammation was defined as a CRP level $\geq 1 \mathrm{mg} / \mathrm{dl}$. Ineffective erythropoiesis was a Reticulocyte Production Index $<2$ [26]. 


\section{Statistical analysis}

Data were double entered using Microsoft Visual FoxPro 5.0 (Microsoft Corp., USA) and analysed using STATA 12 (STATA Corporation, College Station, USA). Crude comparisons were performed by Chi-square or Fisher's exact tests for proportions, and the Student's t test or Wilcoxon rank sum test for means or medians, respectively. Multivariable logistic regression analysis was performed by stepwise selection including all variables with $p$-value $<0.05$ in the crude models, using significance levels of 0.05 and 0.10 for addition to and for removal from the model, respectively. Among the variables with no significant association with anaemia in the univariable model only vitamin B12 and G6PD deficiencies were included in the multivariable model based on biologic plausibility. Intestinal parasitic infections, schistosoma infection, haemoglobinopathy type E, sickle cell trait and $\beta$-thalassaemia trait were not included because of their low prevalence. No children in the control group had clinical malaria or hyperparasitemia, so these variables were not included in the regression models. Due to the difficulty in obtaining sufficient volume of blood samples in some children, $\alpha$-thalassaemia was analysed in only 258 subjects and it was also excluded from the regression analysis. Missing observations were excluded from the multivariate model. Attributable fraction (AF) were estimated using Bruzzi's approach [27]. The variance of adjusted AF (AAF) was approximated by Taylor series to first derivative terms (delta method) [28].

\section{Results}

\section{Characteristics of the participants}

During the study period 736 children were enrolled. Six children were recruited twice and were included in the first group in which they participated; one case older than 5 years of age was excluded. The analysis was restricted to 443 cases and 289 community controls (Fig. 1). Demographic, clinical and socioeconomic characteristics of participants are shown in Tables 1 and 2 .

\section{Risk factors associated with anaemia}

The distribution of risk factors associated with anaemia is summarised in Table 3. Adjusted (for age and sex) Odds Ratios (AOR) from the univariable analysis are shown in Fig. 2.

\section{Undernutrition}

Cases were more wasted, stunted and underweight than controls $(p<0.0001$ for all three parameters, Table 3). Deficiencies in albumin and prealbumin were more prevalent in cases than in controls. ID was found in $69 \%$ $(263 / 381)$ of cases and $43 \%(111 / 260)$ of controls ( $<$ $0.0001)$. ID was more frequent among children with moderate anaemia $[70 \%(241 / 346)]$ than those with severe anaemia $[63 \%(22 / 35)]$ or in controls $[43 \%(111 / 260)$; $p<0.0001$ ]. The crude AF of ID was $47 \%, 95 \%$ CI [39, $55]$ for moderate anaemia and 35\%, 95\%CI [15, 55] for severe anaemia. Vitamin A deficiency was more frequent in cases, while vitamin B12 deficiency was similar in both groups $(p=0.28)$. Folate deficiency was not found.

\section{Bacteraemia}

Cases had a higher prevalence of bacteraemia than controls [8\%(34/433) vs. $1 \%(3 / 286) ; p=0.0001]$. The most commonly isolated bacteria was Streptococcus pneumoniae (32\%). Among the cases, bacteraemia was similar between children with and without ID [7\%(17/258) vs. $8 \%(9 / 115) ; p=0.6649]$.

\section{Viral infections}

Cases had a higher prevalence than controls of infections with HIV [21\%(93/443) vs. $2 \%(6 / 289) ; p<0.0001]$, PV-B19 [6\%(26/443) vs. 2\%(6/287); $p=0.0149]$ and EBV [27\%(117/441) vs. $14 \%(39 / 286) ; p<0.0001]$.

\section{Parasitic infections}

$P f$ infection was present in $42 \%(179 / 428)$ of cases and $7 \%(21 / 287)$ of controls $(p<0.0001)$. Among the cases, the prevalence of clinical malaria was similar between those with ID $[44 \%(114 / 258)]$ and those without it

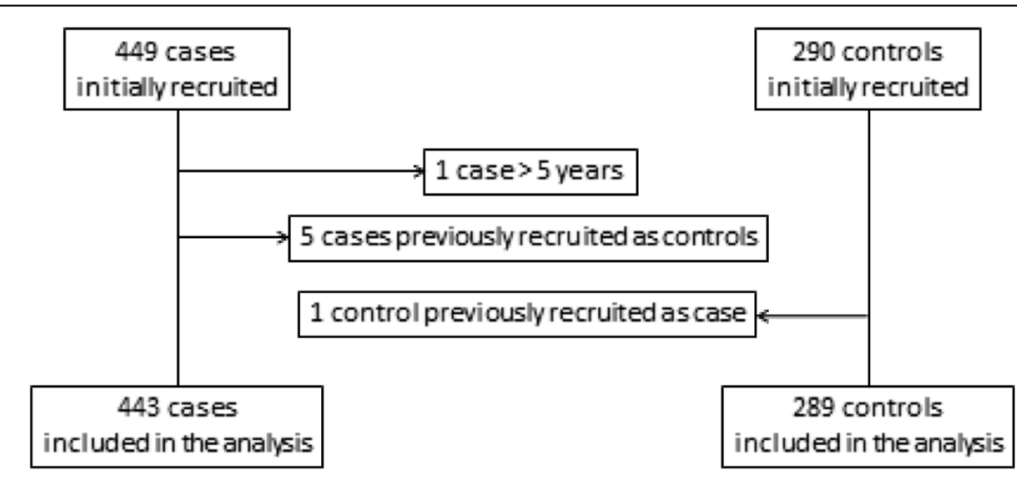

Fig. 1 Recruitment flow chart 
Table 1 Demographic and clinical characteristics of cases and community controls

\begin{tabular}{|c|c|c|c|c|}
\hline \multirow{2}{*}{\multicolumn{2}{|c|}{ Characteristic }} & \multicolumn{2}{|l|}{ Study groups } & \multirow[t]{2}{*}{$p$-value } \\
\hline & & Cases & Controls & \\
\hline \multicolumn{2}{|l|}{ Gender $^{1}$ (male) } & $261 / 443(59 \%)$ & $132 / 289(46 \%)$ & $0.0004^{2}$ \\
\hline \multicolumn{2}{|l|}{ Age (months) ${ }^{3}$} & $19.40(14.08)[443]$ & $26.61(18.51)[289]$ & $<0.0001^{4}$ \\
\hline \multicolumn{2}{|l|}{ Jaundice ${ }^{1}$} & $5 / 443(1 \%)$ & 0/288 (0\%) & $0.1628^{5}$ \\
\hline \multicolumn{2}{|l|}{ Palpable spleen ${ }^{1}$} & 96/443 (22\%) & $1 / 288(0 \%)$ & $<0.0001^{2}$ \\
\hline \multicolumn{2}{|l|}{ Fever $^{1}$} & 389/443 (88\%) & $1 / 289(0 \%)$ & $<0.0001^{2}$ \\
\hline \multicolumn{2}{|l|}{ Haemoglobin $\mathrm{g} / \mathrm{dl}^{3}$} & $7.88(1.98)[443]$ & $11.66(0.75)[289]$ & $<0.0001^{4}$ \\
\hline \multicolumn{2}{|l|}{ Haemoglobin $<5 \mathrm{~g} / \mathrm{dl}^{1}$} & $40 / 443(9 \%)$ & 0/289 (0\%) & $<0.0001^{2}$ \\
\hline \multicolumn{2}{|l|}{$\mathrm{MCV}(\mathrm{fl})^{3}$} & $71.53(9.64)[427]$ & $75.63(7.02)[270]$ & $<0.0001^{4}$ \\
\hline \multicolumn{2}{|l|}{$\mathrm{MCHC}(\mathrm{g} / \mathrm{dl})^{6}$} & $32.60(4.20)[425]$ & $34.00(3.30)[270]$ & $<0.0001^{7}$ \\
\hline \multicolumn{2}{|c|}{ RBC distribution width-sd (fl) ${ }^{6}$} & $45.40(9.60)[420]$ & $41.75(6.10)[270]$ & $<0.0001^{7}$ \\
\hline \multicolumn{2}{|l|}{ White Blood Cells $\left(\times 10^{3} / \mu\right)^{8}$} & $10.54(7.54)[426]$ & $8.75(3.44)[272]$ & $<0.0001^{4}$ \\
\hline \multicolumn{2}{|l|}{$\mathrm{CRP}(\mathrm{mg} / \mathrm{dl})^{6}$} & 5.99 (10.77) [432] & $0.05(0.25)[282]$ & $<0.0001^{7}$ \\
\hline \multicolumn{2}{|l|}{$\mathrm{EPO}(\mathrm{U} / \mathrm{I})^{6}$} & $53.45(176.10)$ [434] & $10.50(7.00)[283]$ & $<0.0001^{7}$ \\
\hline \multicolumn{2}{|l|}{ Inflammation ${ }^{1}$} & $356 / 432(82 \%)$ & $27 / 282(10 \%)$ & $<0.0001^{2}$ \\
\hline \multicolumn{2}{|l|}{ Insufficient erythropoiesis ${ }^{1}$} & $311 / 326(95 \%)$ & $172 / 195(88 \%)$ & $0.0022^{2}$ \\
\hline \multicolumn{2}{|c|}{ Duration of infant admission (days) ${ }^{3}$} & $4.93(4.94)[426]$ & - & \\
\hline \multirow[t]{4}{*}{ Outcome of admission ${ }^{1}$} & Alive & $386 / 425(91 \%)$ & - & \\
\hline & Died & 13/425 (3\%) & - & \\
\hline & Left & $13 / 425(3 \%)$ & - & \\
\hline & Transferred & $13 / 425(3 \%)$ & - & \\
\hline
\end{tabular}

${ }^{1} \mathrm{n} / \mathrm{N}$ (percentage); ${ }^{2}$ Chi-squared test; ${ }^{3}$ Arithmetic mean (SD) [n]; ${ }^{4}$ t-test; ${ }^{5}$ Fisher's exact test; ${ }^{6}$ Median (IQR) [n] ; ${ }^{7}$ Wilcoxon Rank Sum test; ${ }^{8}$ Geometric mean (SD) [n] Abbreviations: CRP C-reactive protein, EPO Erythropoietin, MCHC Mean cell haemoglobin concentration, MCV Mean cell volume, RBC Red blood cells

[40\%(45/111)] $(p=0.5166)$. Among children with severe anaemia, $71 \%(25 / 35)$ had $P f$ parasitemia compared to $39 \%(154 / 393)$ of those with moderate anaemia $(p<$ $0.0001)$. The prevalence of intestinal parasitic infections was low in both groups [controls 6\% (10/154) vs. cases $3 \%(6 / 205) ; p=0.1051)$.

\section{Erythrocyte genetic disorders}

$\alpha$-thalassaemia was found in $53 \%$ of tested children, being more prevalent in cases $[64 \%(77 / 121)$ with $16 \%$ homozygous (a-/a-) and 48\% heterozygous (aa/a-)] than in controls [43\%(59/137) with 15\% homozygous and $28 \%$ heterozygous); $p=0.0010]$. The frequency of G6PD

Table 2 Socioeconomic characteristics of cases and community controls

\begin{tabular}{|c|c|c|c|c|}
\hline \multicolumn{2}{|l|}{ Characteristic } & \multicolumn{2}{|l|}{ Study groups } & \multirow[t]{2}{*}{$p$-value } \\
\hline & & Cases & Controls & \\
\hline \multicolumn{2}{|c|}{$\overline{\text { Mother's age (years) }{ }^{1}}$} & 25.59 (6.31) [376] & $26.50(7.03)[281]$ & $0.0826^{2}$ \\
\hline \multicolumn{2}{|c|}{ Number of children ${ }^{1}$} & $1.73(1.61)[354]$ & $1.99(1.85)[270]$ & $0.0549^{2}$ \\
\hline \multirow[t]{5}{*}{ Marital status ${ }^{3}$} & Married & $17 / 432(4 \%)$ & $7 / 279(3 \%)$ & \multirow[t]{5}{*}{$0.4006^{4}$} \\
\hline & Union & $295 / 432(68 \%)$ & $207 / 279(74 \%)$ & \\
\hline & Maiden & $89 / 432(21 \%)$ & $44 / 279(16 \%)$ & \\
\hline & Separate & $20 / 432(5 \%)$ & $13 / 279(5 \%)$ & \\
\hline & Widow & $11 / 432(3 \%)$ & $8 / 279(3 \%)$ & \\
\hline \multicolumn{2}{|c|}{ Mother was educated ${ }^{3}$} & $255 / 440(58 \%)$ & 199/287 (69\%) & $0.0019^{4}$ \\
\hline \multicolumn{2}{|c|}{ Mother works outside home ${ }^{3}$} & $111 / 443(25 \%)$ & $190 / 289(66 \%)$ & $<0.0001^{4}$ \\
\hline \multicolumn{2}{|c|}{ House of cement ${ }^{3}$} & 149/443 (34\%) & $126 / 289(44 \%)$ & $0.0065^{4}$ \\
\hline \multicolumn{2}{|c|}{ Number of rooms ${ }^{5}$} & $1(1)$ [443] & $2(2)[289]$ & $<0.0001^{6}$ \\
\hline
\end{tabular}

${ }^{1}$ Arithmetic mean (SD) [n]; ${ }^{2}$ t-test; ${ }^{3} \mathrm{n} / \mathrm{N}$ (percentage); ${ }^{4}$ Chi-squared test; ${ }^{5}$ Median (IQR) [n]; ${ }^{6}$ Wilcoxon Rank Sum test 
Table 3 Distribution of possible aetiological and confounding factors of anaemia among cases and community controls

\begin{tabular}{|c|c|c|c|c|c|}
\hline \multirow{2}{*}{\multicolumn{2}{|c|}{ Variable }} & \multicolumn{2}{|l|}{ Study groups } & \multirow[t]{2}{*}{ Total } & \multirow[t]{2}{*}{$p$-value } \\
\hline & & Cases & Controls & & \\
\hline \multicolumn{6}{|c|}{ Undernutrition } \\
\hline \multicolumn{2}{|c|}{ Underweight $(\mathrm{WAZ}<-2)^{1}$} & 197/443 (44\%) & $32 / 284(11 \%)$ & 229/727 (31\%) & $<0.0001^{2}$ \\
\hline \multicolumn{2}{|c|}{ Wasted $(\mathrm{WHZ}<-2)^{1}$} & 134/446 (31\%) & $18 / 280(6 \%)$ & $152 / 716(21 \%)$ & $<0.0001^{2}$ \\
\hline \multicolumn{2}{|c|}{ Stunted $(H A Z<-2)^{1}$} & $141 / 436(32 \%)$ & $35 / 284(12 \%)$ & $176 / 720(24 \%)$ & $<0.0001^{2}$ \\
\hline \multicolumn{2}{|c|}{ Albumin deficiency ${ }^{1}$} & $175 / 432(41 \%)$ & $11 / 282(4 \%)$ & $186 / 714(26 \%)$ & $<0.0001^{2}$ \\
\hline \multicolumn{2}{|c|}{ Prealbumin deficiency ${ }^{1}$} & $389 / 430(90 \%)$ & $97 / 280(35 \%)$ & $486 / 710(68 \%)$ & $<0.0001^{2}$ \\
\hline \multicolumn{2}{|c|}{ Iron deficiency ${ }^{1}$} & $263 / 381(69 \%)$ & $111 / 260(43 \%)$ & $374 / 715(58 \%)$ & $<0.0001^{2}$ \\
\hline \multicolumn{2}{|c|}{ Folate deficiency ${ }^{1}$} & 0/381 (0\%) & 0/255 (0\%) & 0/636 (0\%) & \\
\hline \multicolumn{2}{|c|}{ Vitamin A deficiency $^{1}$} & $301 / 434(69 \%)$ & $79 / 283(28 \%)$ & $380 / 717(53 \%)$ & $<0.0001^{2}$ \\
\hline \multicolumn{2}{|c|}{ Vitamin B12 deficiency ${ }^{1}$} & $68 / 413(16 \%)$ & $53 / 269(20 \%)$ & $121(18 \%)$ & $0.2794^{2}$ \\
\hline \multicolumn{6}{|c|}{ Viral infections } \\
\hline \multirow[t]{4}{*}{$H V^{1}$} & Negative & 297/443 (67\%) & $266 / 289(92 \%)$ & $563(77 \%)$ & $<0.0001^{2}$ \\
\hline & Positive & $93 / 443(21 \%)$ & $6 / 443(2 \%)$ & 99 (14\%) & \\
\hline & Indeterminate & $4 / 443(1 \%)$ & 0/443 (0\%) & $4(1 \%)$ & \\
\hline & Not done & 49/443 (11\%) & $17 / 443(6 \%)$ & $66(9 \%)$ & \\
\hline \multicolumn{2}{|c|}{ Parvovirus B19 infection ${ }^{1}$} & $26 / 436(6 \%)$ & $6 / 287(2 \%)$ & $32 / 730(4 \%)$ & $0.0149^{2}$ \\
\hline \multicolumn{2}{|c|}{ EBV infection ${ }^{1}$} & $117 / 441(27 \%)$ & $39 / 286(14 \%)$ & $156 / 727(21 \%)$ & $<0.0001^{2}$ \\
\hline \multicolumn{2}{|c|}{ Bacteraemia $^{1}$} & $34 / 433(8 \%)^{4}$ & $3 / 286(1 \%)^{5}$ & $37 / 719(5 \%)$ & $0.0001^{2}$ \\
\hline \multicolumn{6}{|c|}{ Parasitic infections } \\
\hline \multicolumn{2}{|c|}{ Plasmodium falciparum ${ }^{1}$} & $179 / 428(42 \%)$ & $21 / 287(7 \%)$ & $200 / 715(28 \%)$ & $<0.0001^{2}$ \\
\hline \multicolumn{2}{|c|}{ Hyperparasitemic Pf. ${ }^{1}$} & $34 / 428(8 \%)$ & $0 / 287(0 \%)$ & $34 / 715$ (5\%) & $<0.0001^{2}$ \\
\hline \multicolumn{2}{|c|}{ Submicroscopic Pf. ${ }^{1}$} & $37 / 322(11 \%)$ & $12 / 284(4 \%)$ & $49 / 666(8 \%)$ & $0.0011^{2}$ \\
\hline \multicolumn{2}{|c|}{ Clinical malaria' ${ }^{1}$} & $172 / 428(40 \%)$ & 0/287 (0\%) & $172 / 715(24 \%)$ & $<0.0001^{2}$ \\
\hline \multicolumn{2}{|c|}{ Intestinal parasites ${ }^{1}$} & $6 / 205(3 \%)^{6}$ & $10 / 154(6 \%)^{7}$ & 16/359 (4\%) & $0.1051^{2}$ \\
\hline \multicolumn{2}{|c|}{ Schistosoma haematobium ${ }^{1}$} & 0/172 (0\%) & 0/175 (0\%) & 0/347 (0\%) & - \\
\hline \multicolumn{6}{|c|}{ Genetic disorders } \\
\hline \multicolumn{2}{|c|}{ G6PD deficiency $^{1}$} & $44 / 436(10 \%)$ & 22/271 (8\%) & $66 / 707(9 \%)$ & $0.3805^{2}$ \\
\hline \multicolumn{2}{|c|}{ Haemoglobinopathy $y^{1,8}$} & 4/431 (1\%) & $2 / 263(1 \%)$ & 6/694 (1\%) & $1.0000^{3}$ \\
\hline \multicolumn{2}{|c|}{$\beta$-Thalassaemia' } & $1 / 431(0 \%)$ & $4 / 263(2 \%)$ & $5 / 694(1 \%)$ & $0.0711^{3}$ \\
\hline a-Thal & & $77 / 121(64 \%)$ & $59 / 137(43 \%)$ & $136 / 258(53 \%)$ & $0.0010^{2}$ \\
\hline
\end{tabular}

${ }^{1} \mathrm{n} / \mathrm{N}$ (column percentage); ${ }^{2}$ Chi-squared test; ${ }^{3}$ Fisher's exact test; ${ }^{4} 11$ Streptococcus pneumoniae, 5 Staphylococcus aureus, 5 Escherichia coli, 3 Salmonella typhimurium, 10 others. ${ }^{5} 1 \mathrm{E}$. coli, 1 Klebsiella spp and $1 \mathrm{~g}$ negative bacilli, lactose fermenting oxidase negative (these findings were considered contaminations or transient bacteraemia); ${ }^{6}$ the intestinal parasites are 3 Ascaris lumbricoides, 2 Giardia lamblia, 1 Strongyloides stercoralis, ${ }^{7}$ the intestinal parasites are 6 Ascaris lumbricoides, 2 Giardia lamblia, 1 Entamoeba hystolitica, 1 Strongyloides stercoralis, ${ }^{8}$ Haemoglobinopathy includes $\mathrm{S}$ and $\mathrm{E}$

Abbreviations: EBV Epstein-Barr virus, G6PD Glucose 6 phosphate dehydrogenase, Pf Plasmodium falciparum, WAZ Weight for age Z score

deficiency was similar in the two groups [cases $10 \%(44 /$ $236)$ vs. controls $8 \%(22 / 271) ; p=0.3805]$. Four children with sickle cell trait but no cases of sickle cell disease were identified. The $\beta$-thalassaemia trait was observed in one case and four controls.

\section{Multivariable analysis}

Age, underweight, deficiencies of prealbumin, albumin and iron, and $P f$ and HIV infections were factors independently associated with anaemia (Table 4). The two main AAF of anaemia were prealbumin deficiency and
ID, $(77 \%, 95 \%$ CI $[69,86]$, and 53\%, 95\% CI, [42, 64], respectively), followed by underweight $(43 \%, 95 \% \mathrm{CI}$ [39; 48]), and $P f$ infection $(37 \%, 95 \%$ CI $[33,41])$. The AAF of anaemia associated with HIV infection was $18 \%$ (95\% CI [13, 22]) (Table 4).

\section{Discussion}

This paper describes a novel study on the aetiology of anaemia in hospitalised children with varying degrees of anaemia. The findings confirm the multifactorial and overlapping aetiology of anaemia and indicate that 


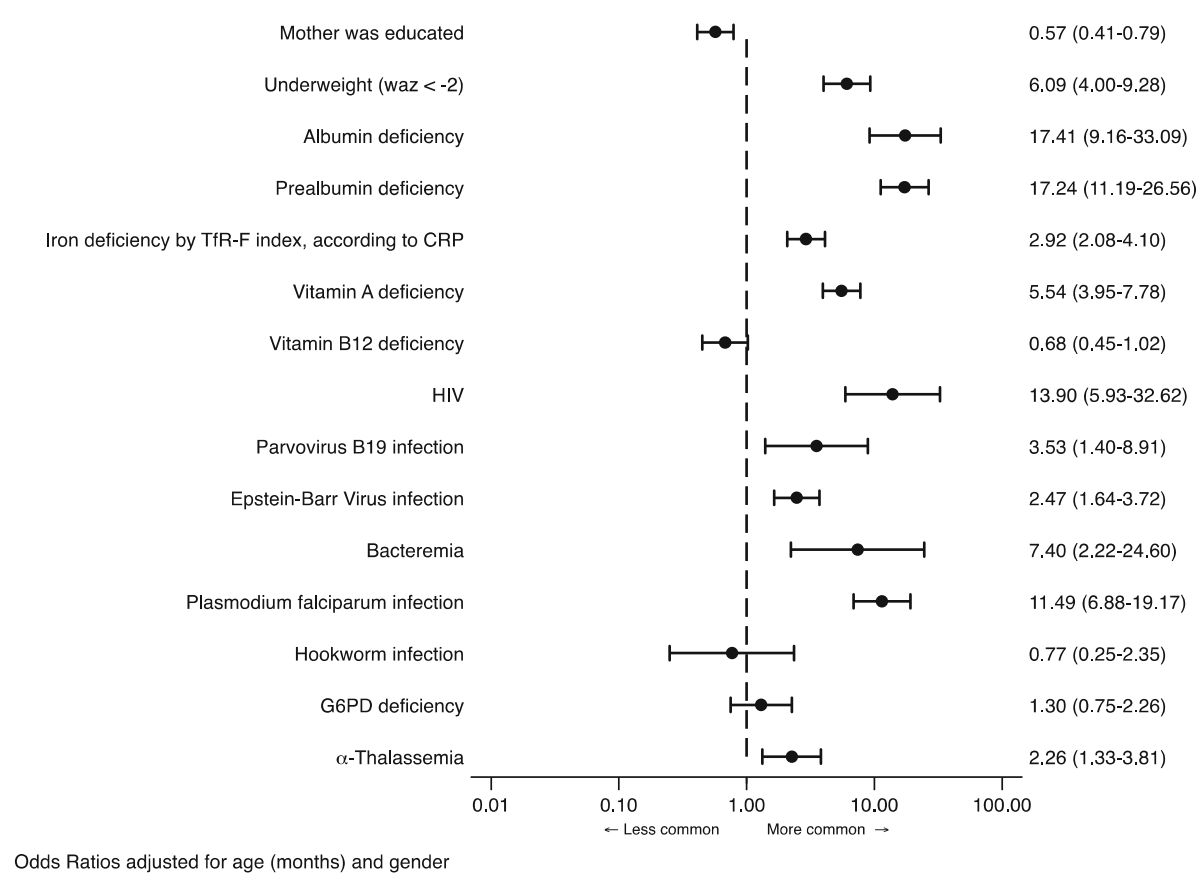

Fig. 2 Odds Ratios adjusted for age and gender for factors associated with anaemia, according groups. Abbreviations: CRP C-reactive protein, G6PD Glucose 6 phosphate dehydrogenase, TfR-F index ratio of soluble transferrin receptor to log ferritin, WAZ Weight for age Z score

undernutrition, ID and malaria and HIV infections are the main factors associated with anaemia. These factors should be prioritised in public health interventions in order to decrease the prevalence of a disease which affects to a $33 \%$ of the world population, mainly children in low resource settings [2].

The extremely high prevalence of overall anaemia in children admitted to the MDH (Moraleda et al., unpublished data) highlights the impact of anaemia among children in this area, which prevented the inclusion of a hospitalised control group. The resulting absence of hospital controls and the absence of a case group from the community could result in an overestimation of the effect of diagnoses associated with hospital admission (including HIV, malaria and other infections), which should be taken into account before extrapolate these results to the nonhospitalised population. On the other hand, as it has been reported, hospital controls may provide weaker or null estimates of the associations compared with community controls because of the high frequency of co-morbidities in this group [29]; for example, it is quite likely that hospital controls may not reveal the association of malaria or HIV with anaemia since these are quite frequent conditions among hospitalised children in this setting.

Table 4 Adjusted odds ratios from logistic regression model and adjusted attributable fractions for anaemia

\begin{tabular}{|c|c|c|c|c|c|c|c|}
\hline \multirow[t]{2}{*}{ Risk factor } & \multirow{2}{*}{$\begin{array}{l}\text { Proportion of } \\
\text { cases with } \\
\text { factor (\%) }\end{array}$} & \multicolumn{3}{|c|}{ Adjusted association } & \multicolumn{2}{|l|}{ AAF } & \multirow[t]{2}{*}{$A C$} \\
\hline & & OR & $(95 \%$ Cl) & $p$-value & Estimate (\%) & $(95 \% \mathrm{Cl})$ & \\
\hline Prealb def. & 90.1 & 7.11 & $(3.55 ; 14.24)$ & $<0.0001$ & 77.42 & $(68.62 ; 86.23)$ & 235 \\
\hline Underweight & 49.2 & 8.10 & $(3.82 ; 17.18)$ & $<0.0001$ & 43.10 & $(38.54 ; 47.67)$ & 131 \\
\hline Pf infection & 42.2 & 8.39 & $(3.82 ; 18.40)$ & $<0.0001$ & 37.21 & $(33.25 ; 41.16)$ & 113 \\
\hline Iron def. & 70.0 & 4.05 & $(2.16 ; 7.61)$ & $<0.0001$ & 52.71 & $(41.85 ; 63.57)$ & 160 \\
\hline Albumin def. & 39.6 & 4.29 & $(1.78 ; 10.35)$ & 0.0012 & 30.37 & $(22.24 ; 38.51)$ & 92 \\
\hline HIV & 21.5 & 5.73 & $(1.65 ; 19.92)$ & 0.0060 & 17.71 & $(13.05 ; 22.37)$ & 54 \\
\hline All risk factors in model & & & & & 97.51 & $(96.16 ; 98.87)$ & 295 \\
\hline
\end{tabular}

Abbreviations: AAF Adjusted attributable fractions, AC Attributable cases, Cl Confidence interval, def: deficiency, Pf Plasmodium falciparum, Prealb Prealbumin, OR Odds Ratio

The odds ratios presented in this table were adjusted for all the variables included in it. In addition, they were also adjusted for the socio-demographic characteristics that were significant in that multivariable model (age and "mother works outside home"). As these variables were protective, their AAF were not calculated 
Albumin and prealbumin deficiencies were very prevalent among cases and nearly 50\% exhibited underweight. Both proteins are markers of malnutrition, but they are also affected by inflammation [30], explaining why these factors were independently associated with anaemia. In contrast, vitamin A deficiency was not independently related to anaemia. This might be attributable to the association of reduced albumin and prealbumin with vitamin A deficiency [31]. On the other hand, vitamin A deficiency might have been overestimated as vitamin A decreases with inflammation [32]. Alternatively, it may also reflect a poor uptake of vitamin A supplementation programs, suggesting that monitoring of the effectiveness of these programs should be considered a critical addition to public health policies.

While CRP test does serve as a general marker for infection and inflammation, it is not specific enough to diagnose a particular disease. Inflammation, defined by an elevated CRP level, was very common among cases (82\%), and thus it was identified as a major risk factor for anaemia. However, this association is difficult to interpret because it actually hides the associations with other underlying factors; for this reason CRP was not included in the multivariable analysis.

In contrast with previous observations in Malawi [33], and similarly to other reports [34], vitamin B12 deficiency was not associated with a risk of anaemia in this study. The general evidence suggests that vitamin B12 deficiency is not a major contributor to anaemia in all settings in Africa.

In this study, folate deficiency was not detected. This may have been underestimated because of difficulties in measuring folate plasma levels [35], or to an increase of folate levels caused by haemolysis during malaria [36]; however, folate levels were also high in children without malaria. Tests with increased sensitivity to measure folate are needed in malaria-exposed populations [35].

The proportion of children with $P f$ parasitemia was increased in those with severe anaemia, suggesting that malaria may contribute more to severe than to moderate anaemia.

Anaemia is one the most frequent signs among HIVinfected children, so the observed association between both conditions was expected [37]. HIV-related anaemia has been mainly associated with uncontrolled HIVdisease, opportunistic infections and nutritional deficiencies, but also to the use of drugs such as zidovudine and cotrimoxazole [38]. At recruitment, the HIV status was known by the relatives in only $44 \%$ of the HIV-infected children of the study and from those less than a quarter were on antiretroviral treatment (most of them including zidovudine) and $11 \%$ referred to be on cotrimoxazole prophylaxis, both with unknown levels of adherence (data not shown). A direct effect of the HIV as one of the main causes of anaemia was expected, but the lack of the RNA-HIV viral loads results limits this conclusion. Other studied aetiologies, such as undernutrition and bacteriemia, seem to have a role in the anaemia of the HIV-infected children in this study (data not shown).

Prevalences of bacteraemia, PV-B19 and EBV infections were higher in cases than in controls, but no independently related to anaemia. This may be due to the association of these infections with other factors included in the model, such as HIV and malaria [33, 39, 40].

Helminthic infections were rare and not associated with anaemia. These findings, consistent with published data among pre-school children [41, 42] and with studies in this same setting where molecular techniques were used (Mandomando et al. unpublished data), are relevant when considering the target age groups of deworming programs.

In agreement with previous observations in Mozambique, the prevalence of sickle cell trait was very low [43]. On the other hand, more than $50 \%$ of those in whom it was tested presented with heterozygous or homozygous $\alpha$-thalassaemia, indicating that mean cell haemoglobin concentration is not a suitable marker of iron status in populations with a high prevalence of the $\alpha$-thalassaemia trait [9]. G6PD deficiency was not associated with an increased risk of anaemia despite most cases harbouring infections, the main risk factor to develop anaemia in children with G6PD deficiency [44].

An important fraction of anaemia was due to ID (AAF $53 \%$ ), indicating that its prevention might have a considerable impact in reducing anaemia prevalence. The association of ID with anaemia was in contrast with data from Malawi where ID was related to a reduced risk of severe anaemia [33]. The authors explain their finding by the observed inverse association between ID and bacteraemia, and the contribution of bacteraemia to anaemia [33]. In the current study, ID was not associated with a reduced prevalence of bacteraemia among cases. The dissimilar observations could be explained by different definitions of study groups, and distinct contributions of ID to anaemia depending on its severity. In the Malawian study, cases were children with severe anaemia and controls were children with $\mathrm{Hb} \geq 5 \mathrm{~g} / \mathrm{dL}$, whereas all degrees of anaemia were included in the cases in the study presented here and controls were not anaemic. The protective effect of ID against severe anaemia in the Malawian study was based on a greater prevalence of ID among controls (most of whom had moderate anaemia). This actually concords with the findings in the present study where ID appeared to contribute more to moderate than to severe anaemia, where other factors might play a more important role. 
Despite the identification of ID as the $4^{\text {th }}$ greatest risk factor for burden of disease in sub-Saharan Africa [1], its prevention in children exposed to malaria remains unresolved. Discrepancies between the Cochrane review, which concludes that iron supplementation does not adversely affect children living in malaria areas [45], and the WHO guidelines which recommend iron supplementation in these areas only if children have proven to be iron deficient [46], leads to the absence of preventive programs for this significant global health problem.

\section{Conclusions}

In hospitalized Mozambican preschool children, undernutrition, and ID were found significantly associated with anaemia, indicating that their prevention may have a major impact. Malaria and HIV infections were also important contributors to anaemia but the impact of their control would be place specific. These findings should inform the development of future interventional studies (such as those focused on iron supplementation or nutritional improvement), which would then guide the design of effective programs to prevent anaemia, a major killer of young children in developing countries.

\section{Abbreviations \\ AAF: Adjusted attributable fractions; AF: Attributable fraction; AOR: Adjusted odds ratio; CISM: Centro de Investigação em Saúde de Manhiça; CRP: C- reactive protein; DSS: Demographic Surveillance System; EBV: Epstein- Barr virus; G6PD: Glucose 6-phosphate dehydrogenase; Hb: Haemoglobin; ID: Iron deficiency; MDH: Manhiça District Hospital; PV-B19: Parvovirus B19; qPCR: real time quantitative PCR; SD: Standard deviations; TfR-F index: Ratio of soluble transferrin receptor to log ferritin; WHO: World Health Organization}

\begin{abstract}
Acknowledgements
The authors are grateful to the parents and their infants participating in the study. We are also grateful to the dedicated staff of the Manhiça District Hospital, as well as the laboratory, clinical, field, and data management staff at the Centro de Investigaçaõ em Saúde de Manhiça, Mozambique and to the investigators from the Hospital Clínic de Barcelona who performed laboratory measurements: Vives Corrons, MD PhD, and Ma del Mar Mañú, BSc PhD, Red Cell Pathology Unit, Biomedical Diagnostic Centre, University Hospital Clínic de Barcelona, Barcelona, Spain, for the erythrocyte genetic disorders; Ramón Deulofeu, PhD, Clinical Biochemistry Laboratory, Hospital Clinic Barcelona, University of Barcelona, Barcelona, Spain, for the vitamins, albumin, prealbumin and iron deficiency marker determinations; and $\mathrm{M}^{\mathrm{a}}$ Ángeles Marcos, MD PhD, Department of Microbiology, Barcelona Centre for International Health Research (CRESIB, Hospital Clínic-Universitat de Barcelona), Barcelona, Spain, for the EBV and PV B19 determinations.
\end{abstract}

\section{Funding}

This study was funded by the Agencia de Cooperación Internacional de Las Illes Balears, Spain and the Fundación Ramón Areces. The Centro de Investigaçaõ em Saúde de Manhiça receives core funding from the Spanish Agency for International Cooperation and Development (AECID). The Walter and Eliza Hall Institute receives Victorian State Government Operational Infrastructure Support and Australian Government NHMRC IRIISS. LS received support as an International Research Scholars of the Howard Hughes Medical Institute and from an NH\&MRC Program Grant \#637406. AHA received support from the Victorian Community Foundation-The George Perry Fund. The funders had no role in the study design, data collection and analysis, decision to publish, or preparation of the manuscript.

\section{Availability of data and materials}

The datasets generated and/or analysed during the current study are available in the Dipòsit Digital de la Universitat de Barcelona repository, http://hdl.handle.net/2445/105664.

\section{Authors' contributions}

CMo, RA, MR, JJA, HM; PA and CM contributed to conception and design of the study; CMo, RA, TN, MR, AN, SA, DN, EM and CM contributed to acquisition of data; CMO, RA, LIQ, JJA and CM analysed the data; all authors contributed to interpretation of data; CMo, RA and CM drafted the article; All authors read, revised the article critically for important intellectual content, and gave final approval of the version to be published.

\section{Competing interests}

The authors declare that they have no competing interests.

\section{Consent for publication}

Not applicable.

\section{Ethics approval and consent to participate}

The study was approved by the National Mozambican Ethics Committee and the Hospital Clínic of Barcelona Ethics Review Committee. All the parents/ guardians of the study children signed the inform consent.

\section{Author details}

${ }^{1}$ ISGlobal, Barcelona Ctr. Int. Health Res. (CRESIB), Hospital Clínic - Universitat de Barcelona, Barcelona, Spain. ${ }^{2}$ Manhiça Health Research Center (CISM), Manhiça, Mozambique. ${ }^{3}$ CIBER Epidemiology and Public Health (CIBERESP), Barcelona, Spain. 'Walter and Eliza Hall Institute for Medical Research, 1G, Royal Parade, Parkville, Victoria 3052, Australia. ${ }^{5}$ Department of Medical Biology, The University of Melbourne, Victoria, Australia. ${ }^{6}$ Australian Institute of Tropical Health and Medicine, James Cook University, PO Box 6811, Cairns QLD 4870, Australia. ${ }^{7}$ National Directorate of Health, Ministry of Health, Maputo, Mozambique.

Received: 20 November 2015 Accepted: 21 February 2017

Published online: 28 February 2017

\section{References}

1. Lim SS, Vos T, Flaxman AD, Danaei G, Shibuya K, Adair-Rohani H, Amann M, Anderson HR, Andrews KG, Aryee M, et al. A comparative risk assessment of burden of disease and injury attributable to 67 risk factors and risk factor clusters in 21 regions, 1990-2010: a systematic analysis for the Global Burden of Disease Study 2010. Lancet. 2012;380(9859):2224-60. doi:10.1016/S0140-6736(12)61766-61768.

2. Kassebaum NJ, Jasrasaria R, Naghavi M, Wulf SK, Johns N, Lozano R, Regan M, Weatherall D, Chou DP, Eisele TP, et al. A systematic analysis of global anemia burden from 1990 to 2010. Blood. 2014;123(5):615-24. doi:10.1182/blood-2013-06-508325.

3. WHO. Worldwide prevalence of anaemia 1993-2005: WHO global database on anaemia. 2008.

4. Brabin BJ, Premii Z, Verhoeff F. An analysis of anemia and child mortality. J Nutr. 2001;131(2S-2):636S-45S. discussion 646S-648S.

5. Mabunda S, Casimiro S, Quinto L, Alonso P. A country-wide malaria survey in Mozambique. I. Plasmodium falciparum infection in children in different epidemiological settings. Malar J. 2008;7:216. do:10.1186/1475-2875-1 187-1216.

6. Martins H. Proposta de componente estratégica dum plano de desenvolvimento nutricional em Moçambique. In. Nutrição Rd, editor. Maputo: MISAU; 2004

7. Omar C, Martins H. Indicadores a utilizar no processo de produção do plano de desenvolvimento sanitario 2000-2005, vol. CNCS/XXIV/98/PA-7. Maputo: Ministery of Health of Mozambique; 1998.

8. WHO, UNICEF. Joint statement by the World Health Organization and the United Nations Children's Fund. Focusing on anaemia. 2004.

9. Aguilar R, Moraleda C, Quinto L, Renom M, Mussacate L, Macete E, Aguilar JL, Alonso PL, Menendez C. Challenges in the diagnosis of iron deficiency in children exposed to high prevalence of infections. PLoS One. 2012;7(11):e50584.

10. Sacoor C, Nhacolo A, Nhalungo D, Aponte JJ, Bassat Q, Augusto O, Mandomando I, Sacarlal J, Lauchande N, Sigauque B, et al. Profile: 
Manhica Health Research Centre (Manhica HDSS). Int J Epidemiol. 2013:42(5):1309-18.

11. Sacarlal J, Nhacolo AQ, Sigauque B, Nhalungo DA, Abacassamo F, Sacoor CN, Aide P, Machevo S, Nhampossa T, Macete EV, et al. A 10 year study of the cause of death in children under 15 years in Manhica, Mozambique. BMC Public Health. 2009;9:67. doi:10.1186/1471-2458-1189-1167.

12. Guinovart C, Bassat Q, Sigauque B, Aide P, Sacarlal J, Nhampossa T, Bardaji A, Nhacolo A, Macete E, Mandomando I, et al. Malaria in rural Mozambique. Part I: children attending the outpatient clinic. Malar J. 2008;7:36.

13. Gonzalez R, Munguambe K, Aponte J, Bavo C, Nhalungo D, Macete E, Alonso P, Menendez C, Naniche D. High HIV prevalence in a southern semi-rural area of Mozambique: a community-based survey. HIV Med. 2012;13(10):581-8

14. MISAU, INS. Inquérito Nacional de Prevalecia, Riscos Comportamentais e Informaçao sobre o HIV e SIDA em Moçambique. INSIDA 2009. Relatorio Preliminar sobre Prevâlencia da Infecçao por HIV. Maputo: Ministerio de Saúde Mozambique \& Instituto Nacional de Saúde; 2010.

15. Moraleda C, de Deus N, Serna-Bolea C, Renom M, Quinto L, Macete E, Menendez C, Naniche D. Impact of HIV exposure on health outcomes in HIV-negative infants born to HIV-positive mothers in Sub-Saharan Africa. J Acquir Immune Defic Syndr. 2014;65(2):182-9. doi:10.1097/QAI. 0000000000000019

16. Nhampossa T, Sigauque B, Machevo S, Macete E, Alonso P, Bassat $Q$ Menendez C, Fumado V. Severe malnutrition among children under the age of 5 years admitted to a rural district hospital in southern Mozambique. Public Health Nutr. 2013;16(9):1565-74. doi:10.1017/ S1368980013001080.

17. Pastor MC, Codoceo R, Deulofeu R, Dolade M, Farré V, Fernandez P, Masia F, Matallana MC, Navarro E, Ortiz de Apodaca A, et al. Procedimiento recomendado para la determinacion de retinol en suero o plasma. Quimica Clínica. 1998;17:38-41.

18. WHO. Sedimentation Method. In: In Basic Laboratory Methods in Medical Parasitology. Geneva: World Health Organization; 1991. p. 33-5.

19. Sapero JJ, Lawless DK. The MIF stain-preservation technic for the identification of intestinal protozoa. AmJTrop Med Hyg. 1953;2(4):613-9.

20. Dode C, Krishnamoorthy R, Lamb J, Rochette J. Rapid analysis of -alpha 3.7 thalassaemia and alpha alpha alpha anti 3.7 triplication by enzymatic amplification analysis. Br J Haematol. 1993;83(1):105-11.

21. Beutler E, Blume KG, Kaplan JC, Lohr GW, Ramot B, Valentine WN. International Committee for Standardization in Haematology: recommended screening test for glucose-6-phosphate dehydrogenase (G-6PD) deficiency. Br J Haematol. 1979;43(3):465-7.

22. CDC. Centers for Disease Control and Prevention Clinical Growth Charts. Available at: http://wwwcdcgov/growthcharts/clinical_chartshtm.

23. Nicholson JF, Pesce MA. Pruebas de laboratorio: Valores de referencia. In: Nelson Textbook of Pediatrics, vol. I. 17th ed. Madrid: Elsevier España; 2004 p. 2396-426.

24. Sanjoaquin MA, Molyneux ME. Malaria and vitamin A deficiency in African children: a vicious circle? Malar J. 2009;8:134.

25. Selhub J, Jacques PF, Dallal G, Choumenkovitch S, Rogers G. The use of blood concentrations of vitamins and their respective functional indicators to define folate and vitamin B12 status. Food Nutr Bull. 2008;29(2 Suppl):S67-73.

26. Ouma C, Keller CC, Davenport GC, Were T, Konah S, Otieno MF, Hittner JB, Vulule JM, Martinson J, Ong'echa JM, et al. A novel functional variant in the stem cell growth factor promoter protects against severe malarial anemia. Infect Immun. 2010;78(1):453-60.

27. Bruzzi P, Green SB, Byar DP, Brinton LA, Schairer C. Estimating the population attributable risk for multiple risk factors using case-control data. Am J Epidemiol. 1985;122(5):904-14.

28. Oehlert GW. A note on the delta method. Am Stat. 1992;46:27-9.

29. Neupane B, Walter SD, Krueger P, Loeb M. Community controls were preferred to hospital controls in a case-control study where the cases are derived from the hospital. J Clin Epidemiol. 2010;63(8):926-31. doi:10.1016/j.jclinepi.2009.1011.1006.

30. Fleck A. Clinical and nutritional aspects of changes in acute-phase proteins during inflammation. Proc Nutr Soc. 1989;48(3):347-54.

31. Rosales FJ, Topping JD, Smith JE, Shankar AH, Ross AC. Relation of serum retinol to acute phase proteins and malarial morbidity in Papua New Guinea children. Am J Clin Nutr. 2000;71(6):1582-8.

32. Wieringa FT, Dijkhuizen MA, West CE, Northrop-Clewes CA, Muhilal. Estimation of the effect of the acute phase response on indicators of micronutrient status in Indonesian infants. J Nutr. 2002;132(10):3061-6.
33. Calis JC, Phiri KS, Faragher EB, Brabin BJ, Bates I, Cuevas LE, de Haan RJ, Phiri Al, Malange P, Khoka M, et al. Severe anemia in Malawian children. N Engl J Med. 2008;358(9):888-99.

34. Metz J. A high prevalence of biochemical evidence of vitamin B12 or folate deficiency does not translate into a comparable prevalence of anemia. Food Nutr Bull. 2008;29(2 Suppl):S74-85.

35. Klee GG. Cobalamin and folate evaluation: measurement of methylmalonic acid and homocysteine vs vitamin B(12) and folate. Clin Chem. 2000; 46(8 Pt 2):1277-83.

36. Bradley-Moore AM, Greenwood BM, Bradley AK, Akintunde A, Attai ED, Fleming AF, Flynn FV, Kirkwood BR, Gilles HM. Malaria chemoprophylaxis with chloroquine in young Nigerian children. IV. Its effect on haematological measurements. Ann Trop Med Parasitol. 1985;79(6):585-95.

37. Ellaurie M, Burns ER, Rubinstein A. Hematologic manifestations in pediatric HIV infection: severe anemia as a prognostic factor. Am J Pediatr Hematol Oncol. 1990;12(4):449-53.

38. Calis JC, van Hensbroek MB, de Haan RJ, Moons P, Brabin BJ, Bates I. HIVassociated anemia in children: a systematic review from a global perspective. Aids. 2008;22(10):1099-112. doi:10.1097/QAD.1090b1013e3282fa1759f.

39. Koduri PR. Parvovirus B19-related anemia in HIV-infected patients. AIDS Patient Care STDs. 2000;14(1):7-11.

40. Moormann AM, Chelimo K, Sumba OP, Lutzke ML, Ploutz-Snyder R, Newton D, Kazura J, Rochford R. Exposure to holoendemic malaria results in elevated Epstein-Barr virus loads in children. J Infect Dis. 2005;191(8):1233-8. Epub 2005 Mar 1239.

41. Kung'u JK, Goodman D, Haji HJ, Ramsan M, Wright VJ, Bickle QD, Tielsch JM, Raynes JG, Stoltzfus R. Early helminth infections are inversely related to anemia, malnutrition, and malaria and are not associated with inflammation in 6to 23-month-old Zanzibari children. Am J Trop Med Hyg. 2009;81 (6):1062-70. doi:10.4269/ajtmh.2009.1009-0091.

42. Kahigwa E, Schellenberg D, Sanz S, Aponte JJ, Wigayi J, Mshinda H, Alonso $P$, Menendez C. Risk factors for presentation to hospital with severe anaemia in Tanzanian children: a case-control study. Trop Med Int Health. 2002;7(10):823-30.

43. Willcox MC, Liljestrand J, Bergstrom S. Abnormal haemoglobins among pregnant women from Mozambique. J Med Genet. 1986;23(2):151-2.

44. Beutler E. G6PD deficiency. Blood. 1994;84(11):3613-36.

45. Okebe JU, Yahav D, Shbita R, Paul M. Oral iron supplements for children in malaria-endemic areas. Cochrane Database Syst Rev. 2011;10:CD006589. doi:10.1002/14651858.CD006589.pub3..

46. WHO. Conclusions and recommendations of the WHO Consultation on prevention and control of iron deficiency in infants and young children in malaria-endemic areas. Food Nutr Bull. 2007;28(4 Suppl):S621-7.

\section{Submit your next manuscript to BioMed Central and we will help you at every step:}

- We accept pre-submission inquiries

- Our selector tool helps you to find the most relevant journal

- We provide round the clock customer support

- Convenient online submission

- Thorough peer review

- Inclusion in PubMed and all major indexing services

- Maximum visibility for your research

Submit your manuscript at www.biomedcentral.com/submit
Biomed Central 